\title{
Metodologia de dosagem e viabilidade em estudo do potencial de aplicação do resíduo de concreto como agregado graúdo para concretos permeáveis sem uso de aditivos
}

O emprego do concreto permeável como pavimento representa um excelente artifício no combate ao fenômeno da impermeabilização superficial urbana. Esta pesquisa envolve a avaliação pioneira sobre a influência da utilização desses resíduos reciclados em substituição à $100 \%$ do agregado convencional de origem pétrea no comportamento mecânico e hidráulico do concreto permeável por meio de ensaios preconizados pela ABNT NBR 16416:2015, sem a utilização de aditivos. Para tanto, realizou-se um estudo de metodologia de dosagem com o intuito de determinar o traço mais adequado para confecção do compósito drenante enquanto pavimento, esperando-se obter um material em conformidade com os requisitos normativos de resistência e permeabilidade, a partir de procedimentos tecnicamente viáveis. Todos os coeficientes de permeabilidade obtidos em laboratório superaram o limite normativo de $0,1 \mathrm{~cm} / \mathrm{s}$, chegando a alcançar valores de até $2,36 \mathrm{~cm} / \mathrm{s}$. Do mesmo modo, obtiveram-se valores médios de resistência característica à compressão das peças ensaiadas próximos ao limite de $20 \mathrm{MPa}$ estipulado pela norma (23,98 MPa e 19,57 MPa, referentes às peças de $60 \mathrm{~mm}$ e $80 \mathrm{~mm}$, respectivamente) e a resistência à tração na flexão foi igualmente atendida: média de 2,08 MPa, superior ao mínimo preconizado (2 MPa). Em vista da perspectiva favorável, os produtos finais poderão ser fabricados em série, reduzindo direta e indiretamente os dispêndios associados ao resíduo da construção civil e à impermeabilização dos pavimentos urbanos.

\section{Methodology of dosage and feasibility in study of the potential of application of concrete waste in total as a great aggregate for permeable concrete without additives}

\begin{abstract}
The use of permeable concrete as a pavement represents an excellent device to combat the phenomenon of urban surface waterproofing. This research involves the pioneering evaluation of the influence of the use of these recycled residues to replace $100 \%$ of the conventional aggregate of stone origin in the mechanical and hydraulic behavior of permeable concrete through tests recommended by ABNT NBR 16416: 2015, without the use of additives. To this end, a dosage study was carried out in order to determine the most suitable mix for making the draining composite while paving, hoping to obtain a material in compliance with the normative requirements of resistance and permeability, from technically viable procedures. All permeability coefficients obtained in the laboratory exceeded the normative limit of $0.1 \mathrm{~cm} / \mathrm{s}$, reaching values of up to $2.36 \mathrm{~cm} / \mathrm{s}$. Likewise, average values of characteristic resistance to compression of the tested pieces were obtained close to the limit of $20 \mathrm{MPa}$ stipulated by the standard (23.98 MPa and $19.57 \mathrm{MPa}$, referring to the $60 \mathrm{~mm}$ and $80 \mathrm{~mm}$ pieces, respectively) and flexural tensile strength was also met: average of $2.08 \mathrm{MPa}$, higher than the recommended minimum (2 MPa). In view of the favorable perspective, the final products may be manufactured in series, directly and indirectly reducing the expenses associated with civil construction waste and waterproofing urban pavements.
\end{abstract}

Keywords: Recycled aggregate; Concrete; Waste management; Sustainability.

Topic: Engenharia Ambiental

Reviewed anonymously in the process of blind peer.
Received: 02/02/2021

Approved: 25/02/2021
Adilson Campos de Paula Junior (D)

Universidade Federal de Juiz de Fora, Brasil

http://lattes.cnpq.br/9017964115410525

http://orcid.org/0000-0002-1997-7087

cpjunior.adilson@gmail.com

\section{Thais Mayra de Oliveira (it}

Universidade Federal de Juiz de Fora, Brasil http://lattes.cnpq.br/9211120062798671 http://orcid.org/0000-0002-2838-6182

thais.mayra@ufjf.edu.br

Antonio Eduardo Polisseni (iD)

Universidade Federal do Rio Grande do Sul, Brasil

http://lattes.cnpq.br/3704033399571967

http://orcid.org/0000-0002-1276-6535

aepolisseni@gmail.com

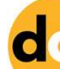

DOI: 10.6008/CBPC2179-6858.2021.002.0032

\author{
Geraldo Luciano de Oliveira Marques (D) \\ Universidade Federal de Juiz de Fora, Brasil \\ http://lattes.cnpq.br/4503245454189660 \\ http://orcid.org/0000-0003-1347-2624 \\ geraldo.marques@ufjf.edu.br \\ Pedro Kopschitz Xavier Bastos (iD \\ Universidade Federal de Juiz de Fora, Brasil \\ http://lattes.cnpq.br/0340779925799164 \\ http://orcid.org/0000-0003-3519-3351 \\ pedrokop@terra.com.br
}

Referencing this:

PAULA JUNIOR, A. C.; OLIVEIRA, T. M.; POLISSENI, A. E.; MARQUES, G. L. O.; BASTOS, P. K. X.. Metodologia de dosagem e viabilidade em estudo do potencial de aplicação do resíduo de concreto como agregado graúdo para concretos permeáveis sem uso de aditivos. Revista Ibero Americana de Ciências Ambientais, v.12, n.2, p.359376, 2021. DOI: http://doi.org/10.6008/CBPC21796858.2021.002.0032 


\section{INTRODUÇÃO}

A diminuição da infiltração do solo urbano gera um acúmulo de água na superfície, intensifica o volume e a velocidade do escoamento superficial, e exige aumento da capacidade de escoamento dos condutos e canais (CARDOSO, 2017). Há também prejuízo para a recarga dos aquíferos, levando à redução do lençol freático, como expõe Acioli (2005). Para mitigar ou até mesmo eliminar as consequências danosas associadas à construção paliativa de enormes sistemas de drenagem, Canholi (2005) entende que é imprescindível a adoção de uma abordagem mais abrangente da gestão das águas, com visão mais integrada entre bacia, ambiente urbano e suas relações.

Neste contexto surgem os estudos sobre pavimentos permeáveis. O concreto, um dos materiais mais utilizados no mundo, não só pode surgir como solução para problemas urbanos associados à impermeabilização superficial, como pode também pode responder a demandas com viés sustentável. O uso de agregados reciclados em sua composição atende, a priori, a esses dois aspectos.

Batezini (2013) afirma que os procedimentos de dosagem, produção e controle tecnológico do concreto permeável como pavimento ainda possuem elevado grau de empirismo, visto que as definições de técnicas e metodologias para realização desses serviços se encontram em fase de pesquisa e adaptação. Assim, o presente trabalho estabeleceu metodologias específicas de dosagem, mistura, moldagem e adensamento do concreto permeável com o intuito de mitigar a variabilidade das características associadas ao próprio concreto permeável, intensificadas pelo emprego de resíduos em sua composição.

Esta pesquisa tem por objetivo desenvolver uma metodologia de dosagem para confecção de concreto permeável destinado à pavimentação urbana, com as seguintes premissas: a) emprego do agregado de concreto reciclado (ACR) agregado graúdo, em substituição total do agregado graúdo convencional; b) sem uso de qualquer tipo de aditivo ou adição; c) atendimento a requisitos de resistência mecânica e condutividade hidráulica para finalidade estudada.

\section{REVISÃO TEÓRICA}

\section{Concreto Permeável}

O concreto permeável (Figura 1), também conhecido como concreto poroso ou drenante, surge para combater os impactos ambientais e toda a problemática associada à impermeabilização urbana, direta ou indiretamente. Além de ser usado como pavimento, favorecendo a infiltração e o retardo do escoamento superficial das águas pluviais, pode ser utilizado também na fabricação de elementos do sistema de drenagem, impedindo o seu entupimento e evitando a entrada de detritos nas tubulações e canalizações (LAMB, 2014).

Como característica, o concreto permeável trata-se, essencialmente, de um material conglomerado poroso constituído por partículas de agregado graúdo de graduação uniforme, revestidas por uma camada espessa de aglomerante hidráulico (normalmente o cimento), que reage com a água de amassamento. Ocasionalmente, são incorporados, ainda, determinados tipos de adições e 
aditivos com o objetivo de alterar positivamente certas propriedades do concreto, conferindo-lhe melhor desempenho, durabilidade, resistência e trabalhabilidade, seja no estado fresco ou no estado endurecido. 0 uso de agregado miúdo é dispensado. Contudo, em certos casos, acrescentam-se pequenas quantidades de areia com o intuito de aumentar o volume da camada de recobrimento, sem acrescer o custo $(\mathrm{ACl}, 2010)$.

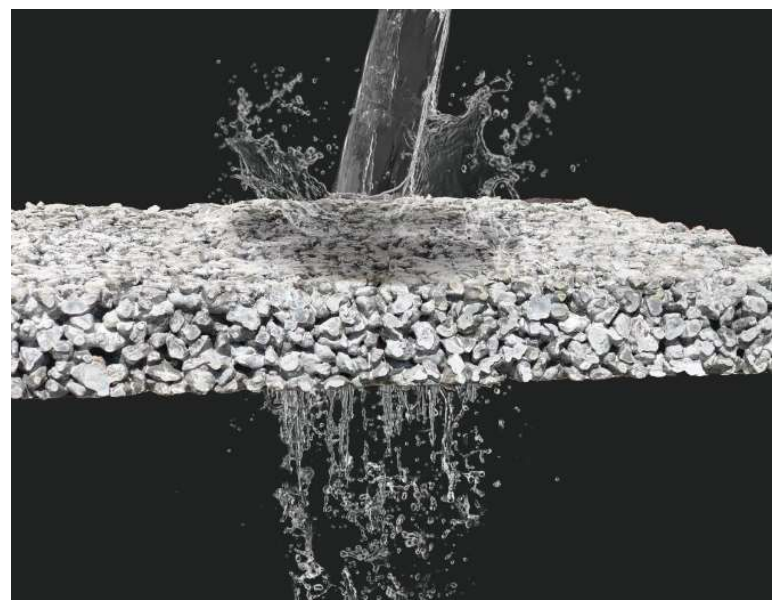

Figura 1: Concreto permeável.

O ligante hidráulico mais usado como aglomerante em concretos permeáveis trata-se do tradicional cimento Portland. Materiais suplementares como a cinza volante, a escória granulada de alto forno moída e a sílica ativa podem, ainda, ser empregados com o intuito de otimizar determinadas propriedades mecânicas do concreto ( $\mathrm{ACl}, 2010)$. Entretanto, para garantir seu potencial permeável, Batezini (2013) salienta que é necessário analisar criteriosamente as proporções dessas adições incorporadas à mistura.

Já os agregados utilizados nas misturas são, normalmente, do tipo uniforme, com diâmetro máximo de $19 \mathrm{~mm}$. Para curvas descontínuas, que apresentam variabilidade do diâmetro do agregado, são usualmente empregadas graduações que variam entre $19 \mathrm{~mm}$ e $4,8 \mathrm{~mm}, 9,5 \mathrm{~mm}$ e 2,4 mm, ou ainda 9,5 mm e 1,2 mm (TENNIS et al., 2004).

Eventualmente são incorporados, ainda, aditivos à mistura, pelo mesmo motivo que são empregados no CCP. Os aditivos superplastificantes tem por objetivo predominante a melhoria da trabalhabilidade das misturas de concreto permeável; já os aditivos retardadores de pega são acrescidos à mistura para controle do tempo de pega, a qual ocorre muito rapidamente no concreto permeável; os aditivos redutores de água são também muito utilizados, dependendo da relação água/cimento (a/c) considerada (NRMCA, 2011).

As proporções desses materiais são definidas por meio de experimentos e procedimentos de dosagem em laboratório, a chamada dosagem experimental (ou racional), na qual devem ser considerados os tipos de insumos disponíveis no local de produção. A Tabela 1 apresenta as faixas de consumo e proporções dos materiais comumente utilizados nas composições de concreto permeável. 
Tabela 1: Consumos e proporções típicos em misturas de concreto permeável.

\begin{tabular}{ll}
\hline Materiais & Consumos/Proporções $\left(\mathrm{kg} / \mathrm{m}^{3}\right)$ \\
\hline Material cimentício $\left(\mathrm{kg} / \mathrm{m}^{3}\right)$ & 270 a 415 \\
Agregado graúdo $\left(\mathrm{kg} / \mathrm{m}^{3}\right)$ & 1.190 a 1.480 \\
Relação água/cimento $(\mathrm{a} / \mathrm{c})$ em massa & 0,27 a 0,34 \\
Relação cimento/agregado em massa & $1: 4$ a $1: 4,5$ \\
Relação agregado miúdo/agregado graúdo em massa & 0 a $1: 1$ \\
\hline
\end{tabular}

Fonte: Tennis et al. (2004).

É válido ressaltar a importância de dois fatores quanto à mistura de concreto permeável: a razão cimento/agregado juntamente ao procedimento de compactação ou adensamento empregado na produção do material. Afinal, são capazes de influenciar diretamente as características mecânicas do compósito, como, por exemplo, a massa específica, que varia, geralmente, entre $1600 \mathrm{~kg} / \mathrm{m}^{3}$ e $2000 \mathrm{~kg} / \mathrm{m}^{3}$ (ACl, 2010).

A NBR 16416 (ABNT, 2015c) não especifica nenhum método quanto à moldagem do concreto permeável. Entretanto, Schaefer et al. (2006) analisaram que a ordem de mistura dos componentes altera a qualidade do produto final. Deste modo, desenvolveram uma metodologia diferente da convencional, onde os agregados são misturados a água e o cimento é adicionado posteriormente. $\mathrm{O}$ novo procedimento elaborado consiste na mistura dos agregados com uma pequena porcentagem de cimento, seguida da adição da água com o restante do aglomerante. Desta maneira, os pesquisadores obtiveram um material com propriedades mecânicas e hidráulicas superiores ao tradicional.

Essa técnica permite obter um material com um índice de vazios entre $15 \%$ e $30 \%$ permitindo a percolação da água proveniente das precipitações por entre os poros da placa de concreto, reduzindo substancialmente o volume de escoamento superficial das águas pluviais. Uma porosidade inferior seria capaz de comprometer as suas propriedades hidráulicas, afirmam Montes et al. (2006).

Segundo Tennis et al. (2004), o índice de vazios e a massa específica próprios do concreto permeável são diretamente influenciados pelas propriedades e proporções relativas dos materiais constituintes, assim como pelo processo de compactação utilizado na sua aplicação. Geralmente, são encontrados valores de massa específica aparente do concreto permeável na ordem de $1.300 \mathrm{~kg} / \mathrm{m}^{3}$ a $2.000 \mathrm{~kg} / \mathrm{m}^{3}$ no estado fresco.

Pesquisas recentes acerca do comportamento mecânico e hidráulico desse compósito atestaram sobre os seus significativos desempenho e durabilidade enquanto revestimento de pavimentos. Quando combinado com seu potencial drenante, possibilita a sua utilização no ambiente urbano como dispositivo minimizador da impermeabilização superficial do solo, acentuada devido ao fenômeno de urbanização das cidades (PINTO, 2011).

De acordo com a norma americana $\mathrm{ACl}$ 522R-10 ( $\mathrm{ACl}, 2010)$, os compostos de concreto permeável tendem a desenvolver resistências mecânicas de compressão na faixa de 2,8 a 28 MPa; já alguns autores em 2006 asseguram que, em média, são obtidos valores de resistência dos concretos permeáveis normalmente produzidos por volta de $25 \mathrm{MPa}$. 
No entanto, Lamb (2014) afirma que seu uso é muitas vezes restrito a áreas de tráfego leve ou pouco intenso, devido à sua alta porosidade, o que torna os valores de resistência desse concreto inferiores aos do concreto convencional. De fato, o alto índice de vazios do material possui uma relação intrínseca às características de resistência mecânica no seu estado endurecido (BATEZINI, 2013).

Ainda segundo Batezini (2013), o compósito é denominado de baixa porosidade quando seu índice de vazios é inferior a 15\%; já um índice de vazios superior a 30\%, descreve um material altamente poroso. Já Olek et al. (2003) indicam que a média do índice de vazios do concreto permeável varia entre $15 \%$ e 35\%. Entretanto, valores muito acima de 30\% ocasionariam níveis muito inferiores de resistência.

Embora os autores divirjam acerca do limite superior desse parâmetro, todos confluem quanto à necessidade da busca por um valor ótimo que garanta concomitantemente boas características de resistência e permeabilidade.

\section{METODOLOGIA}

\section{Materiais Utilizados}

Para a confecção do concreto selecionou-se o cimento CP V-ARI como aglomerante, buscando-se tempos menores de desforma de corpos-de-prova em laboratório. Além disso, a rapidez na pega também é importante considerando-se que concreto permeável, devido à sua elevada superfície exposta ao ar, tende a perder água de mistura mais rapidamente. A alta reatividade do CP V-ARI nas primeiras horas de aplicação do concreto contribui para o menor preenchimento de poros durante a formação do conglomerado (HÖLTZ, 2011).

A particularidade deste trabalho quanto à composição do concreto permeável se dá pela utilização total dos resíduos de construção civil (RCC): resíduos de concreto (Figura 2). Resíduos dessa categoria são classificados como classe A, segundo a Resolução CONAMA no 307 (CONAMA, 2002), ou como classe II B, conforme a NBR 10004 (ABNT, 2004).

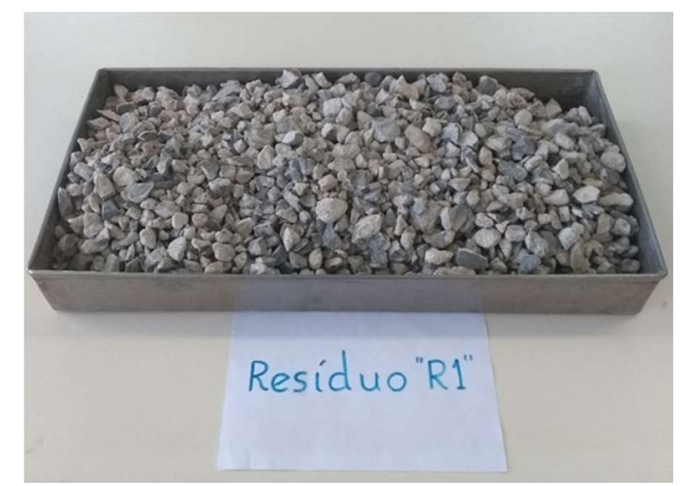

Figura 2: Resíduo de concreto triturado.

Esse material, proveniente de obras de construção e demolição, foi coletado, triturado e peneirado, determinando-se o emprego exclusivo da faixa granulométrica com material passante na peneira de abertura 
$25 \mathrm{~mm}$ e retido na peneira 9,5 mm, segundo a NBR 7211 (ABNT, 2009a). Por se tratar de RCC, a granulometria do agregado tende a variar, visto que as partículas dos materiais se desagregam com maior facilidade. 0 controle de produção adotado neste trabalho incluiu a caracterização física de todo o resíduo utilizado (Tabela 2).

Tabela 2: Propriedades físicas das amostras de resíduos.

\begin{tabular}{lll}
\hline Caracterização Física & \\
\hline Propriedade & Norma técnica & $\begin{array}{l}\text { Amostra de Resíduos } \\
\text { (Valores médios) }\end{array}$ \\
\hline Massa específica real $\left(\mathrm{g} / \mathrm{cm}^{3}\right)$ & ABNT NBR NM 53:2009 & 2,76 \\
Absorção de água $(\%)$ & ABNT NBR NM 53:2009 & 4,2 \\
Massa unitária $\left(\mathrm{g} / \mathrm{cm}^{3}\right)$ & ABNT NBR NM 45:2006 & 1,25 \\
Teor de material pulverulento (\%) & ABNT NBR NM 46:2003 & 0,43 \\
Abrasão Los Angeles (\%) & ABNT NBR NM 51:2001 & 44,6 \\
\hline
\end{tabular}

\section{Metodologia de Dosagem}

Como não há, ainda, metodologias normatizadas para dosagem de concreto permeável, foi desenvolvido um estudo de dosagem experimental com o objetivo de estabelecer a melhor proporção dos constituintes do compósito. Essa metodologia consiste, fundamentalmente, em fixar um valor de massa específica para o concreto permeável de acordo com a NBR (ABNT, 2015b), que classifica como concreto leve aquele que apresenta, para esta propriedade, valor inferior a $2000 \mathrm{~kg} / \mathrm{m}^{3}$, e, por conseguinte, encontrar as quantidades de agregado graúdo e de cimento necessários à mistura, em massa.

O valor de massa específica do concreto permeável estipulado neste trabalho, de $1600 \mathrm{~kg} / \mathrm{m}^{3}$ corresponde ao limite mínimo a ser especificado em projeto, conforme a NBR 16416 (ABNT, 2015). Foi adotada a relação água/cimento igual a 0,35; estimada com base no elevado teor de absorção esperado do resíduo a ser empregado na produção do compósito. O último parâmetro fundamental para o cálculo do consumo de cimento é a quantidade de vazios, que no concreto convencional é de 1 a $2 \%$ e, no concreto permeável, mais poroso, é estimado entre 15 e 35\%.

Adotando-se o valor de 350 litros como volume de vazios (referente ao maior teor encontrado na literatura: 35\%), foi definido o traço do concreto permeável: 1: 3,780 (cimento: agregado graúdo,) em proporções de massa, relação água cimento igual a 0,35 e com consumo de cimento (C) de a $312 \mathrm{~kg} / \mathrm{m}^{3}$.

\section{Planejamento experimental}

Os experimentos foram conduzidos de forma a testar tanto propriedades mecânicas, como propriedades hidráulicas. A Tabela 3 apresenta a o planejamento da etapa laboratorial e a Figura 3 (a) e (b) apresentam os processos de adensamento realizados, com auxílio de bastão e soquete metálicos para a moldagem dos prismas e das placas.

Tabela 3: Amostragem dos corpos de prova.

\begin{tabular}{|c|c|c|c|c|c|c|}
\hline \multirow{3}{*}{ Ensaio } & \multicolumn{6}{|c|}{ Tipo de corpo de prova } \\
\hline & \multirow{2}{*}{ Cilindro } & \multirow{2}{*}{ Prisma } & \multicolumn{2}{|c|}{ Bloco $(50 \times 100 \times \mathrm{e}) \mathrm{mm}$} & \multicolumn{2}{|c|}{ Placa $(750 \times 750 \times$ e) $\mathrm{mm}$} \\
\hline & & & $e=60 \mathrm{~mm}$ & $e=80 \mathrm{~mm}$ & $e=60 \mathrm{~mm}$ & $e=80 \mathrm{~mm}$ \\
\hline Massa específica no estado endurecido & 12 & - & 15 & 15 & - & - \\
\hline
\end{tabular}




\begin{tabular}{|c|c|c|c|c|c|c|}
\hline \multirow{3}{*}{ Ensaio } & \multicolumn{6}{|c|}{ Tipo de corpo de prova } \\
\hline & \multirow{2}{*}{ Cilindro } & \multirow{2}{*}{ Prisma } & \multicolumn{2}{|c|}{ Bloco $(50 \times 100 \times$ e) $\mathrm{mm}$} & \multicolumn{2}{|c|}{ Placa $(750 \times 750 \times$ e $) \mathrm{mm}$} \\
\hline & & & $\mathrm{e}=60 \mathrm{~mm}$ & $\mathrm{e}=80 \mathrm{~mm}$ & $\mathrm{e}=60 \mathrm{~mm}$ & $\mathrm{e}=80 \mathrm{~mm}$ \\
\hline Índice de vazios & 12 & - & 15 & 15 & - & - \\
\hline Resistência à compressão axial & 16 & - & - & - & - & - \\
\hline Resistência à tração na flexão & - & 4 & - & - & - & - \\
\hline Resistência à compressão & - & - & 15 & 15 & - & - \\
\hline Velocidade de propagação de ondas ultrassônicas & 12 & - & - & - & - & - \\
\hline Módulo de elasticidade dinâmico & 12 & - & - & - & - & - \\
\hline Coeficiente de permeabilidade & - & - & - & - & 3 & 3 \\
\hline
\end{tabular}

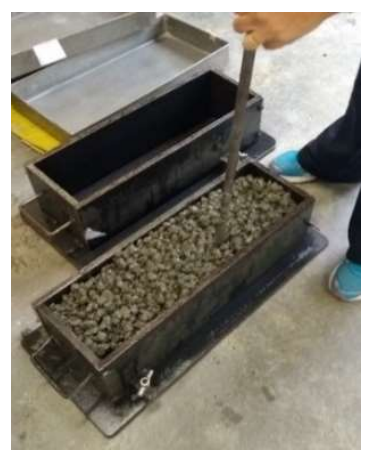

(a)

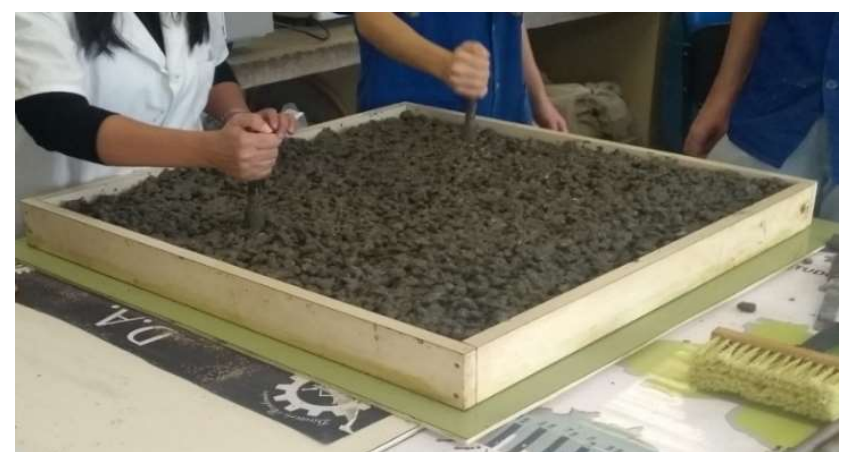

(b)

Figura 3: Moldagem de prisma (a) e placa (b) de concreto permeável.

\section{Modelos reais}

Após a realização de todos os ensaios de caracterização técnica, propôs-se a implantação de modelos reais de pavimentação para avaliação, em campo, das propriedades hidráulicas do material estudado. Foram pavimentadas uma área de 2,5 × 5,0 (m), de tamanho equivalente ao da vaga de um veículo de passeio, com concreto misturado in loco, e uma área de 2,0 $\mathrm{m}^{2}$ em uma calçada, com as placas quadradas.

Para as camadas inferiores, foram utilizados materiais pétreos de granulometria aberta, conforme especificação normativa. Ainda de acordo com as características apresentadas pelo subleito, foi adotado o sistema de drenagem parcial, em que uma pequena parte da água precipitada se infiltra pelo próprio solo. Contudo, a maior parte da água permanece temporariamente armazenada na estrutura do concreto permeável, removida posteriormente pelo dreno instalado, ao qual foi dado um caimento de $2 \%$.

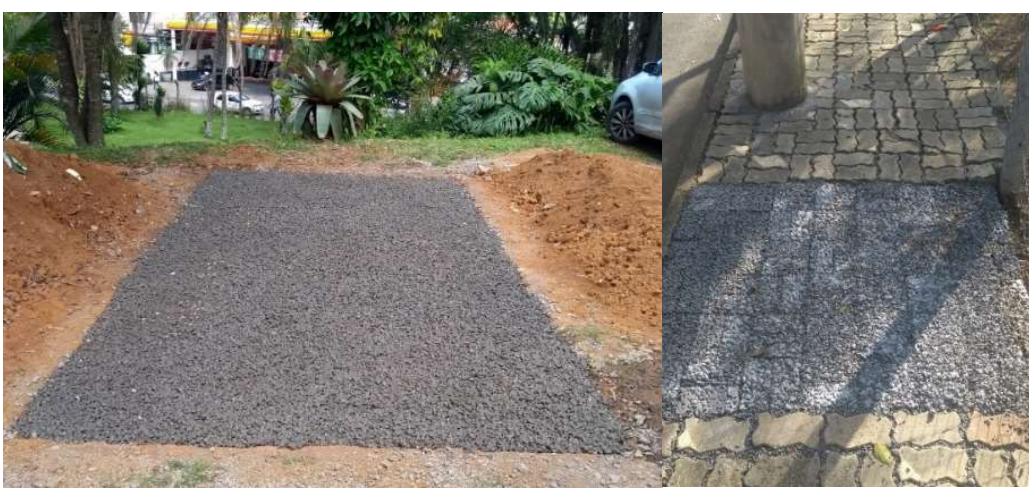

(a)

(b)

Figura 4: Vaga de estacionamento (a) e segmento de calçada com blocos intertravados (b) experimentais de concreto permeável produzido com agregado reciclado.

As etapas de lançamento, adensamento e nivelamento foram feitas de modo a apenas acomodar as 
partículas em camadas regulares e regularizar a superfície. Para moldagens in loco, por conta da menor retração apresentada pelo concreto permeável, permite-se a ausência de juntas em placas inferiores a seis metros de comprimento, limitadas pela NRMCA (2004), vide Figura 4 (a) e (b).

\section{RESULTADOS}

Foram realizadas seis misturas de concreto ao longo de todo o estudo. Além das quatro destinadas aos ensaios de laboratório, duas concretagens destinadas aos modelos reais. Os valores em vermelho acompanhados de asterisco, não foram considerados no cálculo das médias apresentadas, pois, segundo o método estatístico adotado, baseado na Amplitude Interquartil, descrito por Navidi (2015), esses dados consistem em outliers. As Tabelas 4 a 11 apresentam os resultados encontrados nos diferentes tipos de ensaios de caracterização e verificação das amostras analisadas.

\section{Massa específica no estado fresco}

Conforme a NBR 16416 (ABNT, 2015c), toda concretagem foi seguida da obtenção da massa específica do concreto fresco, avaliada por método de ensaio de acordo com a NBR 9833 (ABNT, 2008b), vide Tabela 4.

Tabela 4: Resultados de massa específica no estado fresco de cada concretagem realizada.

\begin{tabular}{l|l|l}
\hline Concretagem & Destinação & Massa Específica no Estado Fresco $\left(\mathbf{k g} / \mathbf{m}^{\mathbf{3}}\right)$ \\
\hline 1 & & 1732,4 \\
2 & \multirow{3}{*}{ Ensaios de caracterização } & 1702,4 \\
\cline { 3 - 3 } 3 & & 1647,0 \\
\cline { 3 - 3 } 4 & & 1681,8 \\
\hline 5 & Blocos passeio & 1678,4 \\
\hline 6 & Vaga do estacionamento & 1622,6 \\
\hline
\end{tabular}

\section{Massa específica no estado endurecido e índice de vazios}

Os valores individuais referentes à massa especificam no estado endurecido e ao índice de vazios obtidos nos corpos de prova cilíndricos, rompidos aos 28 dias, quanto aos blocos para pavimentação intertravada com 60 e $80 \mathrm{~mm}$ de espessura apresentam-se na Tabelas 5.

Tabela 5: Resultados dos ensaios de massa específica no estado endurecido e índice de vazios

\begin{tabular}{|c|c|c|c|c|c|c|c|c|c|}
\hline \multicolumn{3}{|c|}{ Corpos de Prova Cilíndricos } & \multicolumn{3}{|c|}{$\begin{array}{l}\text { Bloco de Concreto Permeável ( } 60 \mathrm{~mm} \text { de } \\
\text { espessura) }\end{array}$} & \multicolumn{4}{|c|}{$\begin{array}{l}\text { Bloco de Concreto Permeável ( } 80 \mathrm{~mm} \text { de } \\
\text { espessura) }\end{array}$} \\
\hline Análise & $\begin{array}{l}\text { M. Esp. } \\
\left(\mathrm{kg} / \mathrm{m}^{3}\right)\end{array}$ & $\begin{array}{l}\text { Índ. Vazios } \\
\text { (\%) }\end{array}$ & Análise & $\begin{array}{l}\text { M. Esp. } \\
\left(\mathrm{kg} / \mathrm{m}^{3}\right)\end{array}$ & $\begin{array}{l}\text { Índ. Vazios } \\
\text { (\%) }\end{array}$ & Análise & $\begin{array}{l}\text { M. } \\
\left(\mathrm{kg} / \mathrm{m}^{3}\right)\end{array}$ & Esp. & $\begin{array}{l}\text { Índ. Vazios } \\
\text { (\%) }\end{array}$ \\
\hline & 1873,5 & 20,65 & & 2175,3 & 24,83 & & 1713,3 & & 27,36 \\
\hline & 1944,7 & 17,14 & & 1893,2 & 31,61 & & 1859,3 & & 16,88 \\
\hline & 1922 & 22,78 & & 2059,8 & 28,04 & & 1891,4 & & 16,64 \\
\hline & 2006,4 & 13,97 & & 2070,9 & 11,16 & & $1629,8^{*}$ & & 31,19 \\
\hline & 1938,1 & 16,88 & & 1901,4 & 18,85 & & 1703,8 & & 26,98 \\
\hline & 1885,9 & 32,02 & & 1933,4 & 18,58 & & 1878,7 & & 16,56 \\
\hline & 1821,3 & 25,03 & & 1983,5 & 15,26 & & 1794,5 & & 19,85 \\
\hline & 1886,3 & 27,74 & & 2020 & 13,55 & & 1924,4 & & 15,08 \\
\hline & 1787,9 & 33,67 & & 1906,4 & 19,61 & & 1918,1 & & 14,23 \\
\hline & $2114,1 *$ & 35,19 & & 2059,6 & 14,32 & & 1779,3 & & 22,71 \\
\hline & 1755 & 27,97 & & 1996,1 & 14,76 & & 1820,9 & & 20,6 \\
\hline
\end{tabular}


Metodologia de dosagem e viabilidade em estudo do potencial de aplicação do resíduo de concreto como agregado graúdo para concretos

\begin{tabular}{|c|c|c|c|c|c|c|c|c|}
\hline & \multirow[t]{4}{*}{1916,7} & \multirow[t]{4}{*}{17,35} & & 1818,4 & \multicolumn{2}{|l|}{29,73} & \multirow{2}{*}{$\begin{array}{l}1914,8 \\
1973,8\end{array}$} & \multirow{2}{*}{$\begin{array}{l}21,56 \\
13,15\end{array}$} \\
\hline & & & & 2000,8 & 14,57 & & & \\
\hline & & & & 2101,8 & 10,32 & & 1937,5 & 15,03 \\
\hline & & & & 2178 & 28,3 & & 1864,1 & 18,77 \\
\hline Média & 1885,3 & 24,2 & Média & 2006,6 & 19,56 & Média & 1855,3 & 19,77 \\
\hline Desvio Padrão & 73,49 & 7,19 & Desvio Padrão & 104,28 & 7,13 & Desvio Padrão & 82,63 & 5,35 \\
\hline $\begin{array}{l}\text { Coef. de } \\
\text { Variação (\%) }\end{array}$ & 3,9 & 29,71 & $\begin{array}{l}\text { Coef. de } \\
\text { Variação (\%) }\end{array}$ & 5,2 & 36,46 & $\begin{array}{l}\text { Coef. de } \\
\text { Variação (\%) }\end{array}$ & 4,45 & 27,07 \\
\hline
\end{tabular}

\section{Outlier*}

\section{Resistência à compressão axial}

A Tabela apresenta os resultados de resistência à compressão axial (NBR 5739 (ABNT, 2018a)) de todos os 16 corpos de prova cilíndricos moldados subdivididos quanto à idade de rompimento: 7, 14 e 28 dias.

Tabela 6: Resultados dos ensaios de resistência à compressão axial.

\begin{tabular}{ll}
\hline Corpos de Prova Cilíndricos & \\
\hline Resistência à Compressão Axial (MPa) & Resultado \\
\cline { 2 - 2 } Idade do Ensaio & $\mathbf{1}$ \\
\hline (dias) & 7,43 \\
\hline 7 & 8,85 \\
\hline 14 & 15,93 \\
\hline & 11,85 \\
\hline & 15,80 \\
& 12,36 \\
& 18,90 \\
& 16,49 \\
& 17,93 \\
& 22,95 \\
& 17,57 \\
\hline Média & 18,39 \\
\hline Desvio Padrão & 20,85 \\
\hline Coef. de Variação (\%) & 15,25 \\
\hline Outlier* & $\mathbf{7 , 3 9 *}$ \\
\hline
\end{tabular}

\section{Resistência à Tração na Flexão}

Os resultados dos ensaios de determinação de resistência à tração na flexão conforme NBR 12142 (ABNT, 2010), realizados aos 28 dias, aos quais foram submetidos os 4 corpos de prova prismáticos compostos, vide Tabela 7.

Tabela 7: Resultados dos ensaios de resistência à tração na flexão aos 28 dias.

\begin{tabular}{ll}
\hline Corpos de Prova Prismáticos (Prismas) & \\
\hline Amostra & Resistência à Tração na Flexão (MPa) \\
\hline 1 & 2,24 \\
2 & 2,24 \\
3 & 2,14 \\
4 & 2,01 \\
\hline Média & 2,08 \\
Desvio Padrão & 0,09
\end{tabular}


A Figura 5 é apresenta as condições de rompimento do concreto permeável com agregado reciclado, salientando a mudança no comportamento mecânico do material.

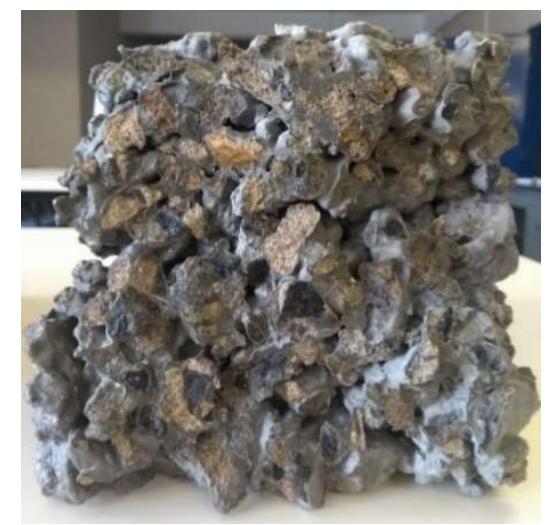

Figura 5: Corpo de prova prismático de concreto permeável produzido com resíduo de concreto após o rompimento.

\section{Resistência à compressão dos blocos}

Os valores referentes aos blocos de concreto permeável para pavimentação intertravada, com 60 e $80 \mathrm{~mm}$ de espessura, ensaiadas quanto à resistência à compressão aos 28 dias, são apresentados na Tabela 1, bem como a resistência característica à compressão estimada conforme NBR 9781 (ABNT, 2013).

Tabela 1: Resultados dos ensaios de resistência característica à compressão aos 28 dias.

\begin{tabular}{|c|c|c|}
\hline \multicolumn{3}{|l|}{ Blocos de Concreto Permeável } \\
\hline Espessura $(\mathrm{mm})$ & 60 & 80 \\
\hline \multirow{15}{*}{ Resistência à Compressão (MPa) } & $39,20 *$ & 14,04 \\
\hline & 17,90 & 19,40 \\
\hline & 27,36 & 22,03 \\
\hline & 29,16 & 16,49 \\
\hline & 21,29 & 11,59 \\
\hline & 23,51 & 19,29 \\
\hline & 22,28 & 23,23 \\
\hline & 32,17 & 21,24 \\
\hline & 24,01 & 29,73 \\
\hline & $37,07 *$ & 13,06 \\
\hline & 21,04 & 15,66 \\
\hline & 22,85 & 22,70 \\
\hline & 18,74 & 24,91 \\
\hline & 28,68 & 22,48 \\
\hline & 22,76 & 17,75 \\
\hline Média & 23,98 & 19,57 \\
\hline Desvio Padrão & 4,22 & 4,91 \\
\hline Coeficiente de Variação (\%) & 17,60 & 25,07 \\
\hline$f_{p k \text {, est }}$ & 20,30 & 15,32 \\
\hline
\end{tabular}

\section{Outlier*}

A NBR 16416 (ABNT, 2015c) limita a resistência à compressão a valores superiores a 20 MPa para revestimento de pavimento constituído por blocos de concreto permeável, seja para tráfego de pedestres, cuja espessura mínima é de $60 \mathrm{~mm}$, ou para tráfego leve, este com espessura mínima de $80 \mathrm{~mm}$. 


\section{Módulo de elasticidade dinâmico}

Na Tabela apresentam-se os resultados de módulo de elasticidade dinâmico relativos a cada corpo de prova cilíndrico cujo rompimento se deu aos 28 dias, submetido ao ensaio de determinação de velocidade de propagação de onda ultrassônica. A média de todos os valores assim como o desvio padrão e o coeficiente de variação obtidos para os CPs correspondentes são expostos em seguida.

Tabela 9: Resultados dos ensaios de módulo de elasticidade dinâmico em corpos de prova cilíndricos.

\begin{tabular}{ll}
\hline Módulo de Elasticidade (GPa) & \\
\hline 16,18 & 12,78 \\
10,99 & 12,13 \\
15,56 & 12,99 \\
15,29 & $21,53^{*}$ \\
14,38 & 11,71 \\
$4,28^{*}$ & 12,06 \\
\hline Média & 13,41 \\
Desvio Padrão & 1,812 \\
Coeficiente de Variação (\%) & 13,52 \\
\hline
\end{tabular}

\section{Outlier*}

\section{Coeficiente de Permeabilidade}

Os valores obtidos através do ensaio de permeabilidade realizado nas placas de concreto permeável são exibidos na Tabela 10. Cada placa, tendo ela 60 ou $80 \mathrm{~mm}$ de espessura, foi submetida a dois ensaios consecutivos (Figura 6), respeitando as exigências normativas NBR 13292 (ABNT, 1995) quanto à execução.

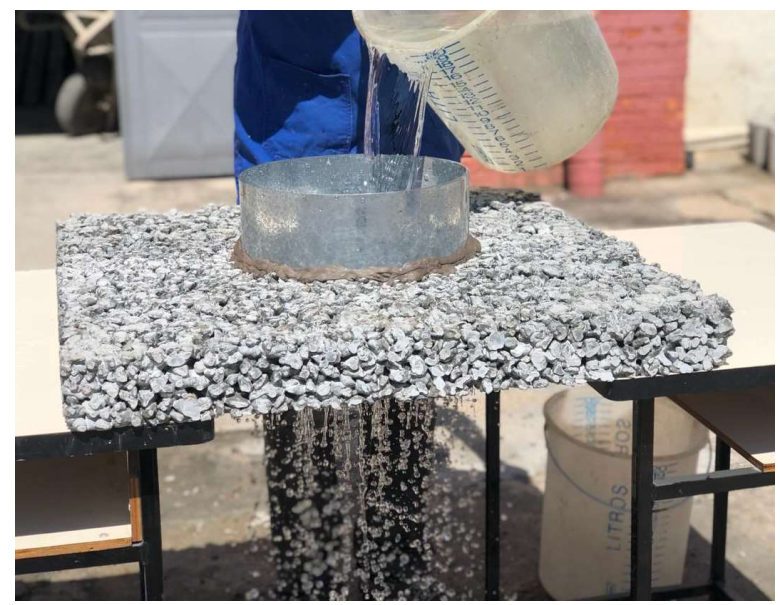

Figura 6: Ensaio de determinação do coeficiente de permeabilidade.

Tabela 10: Resultados dos ensaios de determinação do coeficiente de permeabilidade.

\begin{tabular}{lll}
\hline Coeficiente de Permeabilidade & & \\
\hline Espessura $(\mathbf{m m})$ & Placa & Coeficiente de Permeabilidade $(\mathrm{cm} / \mathrm{s})$ \\
\hline & 1 & 1,32 \\
& & 1,38 \\
& Média & 1,35 \\
\cline { 2 - 3 } 60 & 2 & 0,89 \\
& & 0,92 \\
& Média & 0,90 \\
\cline { 2 - 3 } & 3 & 0,44 \\
& & 0,43 \\
& & 0,44 \\
\hline 80 & Média & 1,61 \\
\hline
\end{tabular}




\begin{tabular}{|c|c|c|c|}
\hline & & 1,60 & \\
\hline & Média & 1,60 & \\
\hline & & 1,25 & \\
\hline & 5 & 1,56 & \\
\hline & Média & 1,41 & \\
\hline & 6 & 2,29 & \\
\hline & 0 & 2,43 & \\
\hline & Média & 2,36 & \\
\hline \multirow{3}{*}{ Dados } & & Coeficiente de Permeabilidade $(\mathrm{cm} / \mathrm{s})$ & \\
\hline & & Espessura da Placa & \\
\hline & & $60 \mathrm{~mm}$ & $80 \mathrm{~mm}$ \\
\hline Média & & 0,90 & 1,79 \\
\hline Desvio Padrão & & 0,46 & 0,51 \\
\hline Coeficiente de Variação (\%) & & 50,89 & 28,25 \\
\hline
\end{tabular}

\section{Modelos Reais}

Determinação da massa específica do concreto fresco para os blocos do passeio e para a vaga do estacionamento: $1678,4 \mathrm{~kg} / \mathrm{m}^{3}$ e $1622,6 \mathrm{~kg} / \mathrm{m}^{3}$, respectivamente. Determinação do coeficiente de permeabilidade, realizados tanto no concreto moldado diretamente na vaga de estacionamento quanto nos blocos para pavimentação intertravada: $2,46 \mathrm{~cm} / \mathrm{s}$ e 3,03 cm/s, respectivamente.

\section{Microscopia de luz transmitida e difração de raios $X$}

Foi analisado, também, em cooperação com a Associação Brasileira de Cimento Portland ( $A B C P)$, o comportamento microscópico do material produzido. Um dos blocos de concreto permeável fabricado foi submetida a ensaios de microscopia de luz transmitida e de difratometria de raios X. A partir da fotomicrografia com nicóis (filtros polarizados) descruzados (Figura 7 (a) e (b)) é possível observar os agregados graúdos reciclados $(G)$ envolvidos pela pasta $(P)$. Na porção inferior da imagem identifica-se um poro do concreto permeável. Vale salientar o contato abrupto entre pasta e agregado reciclado.

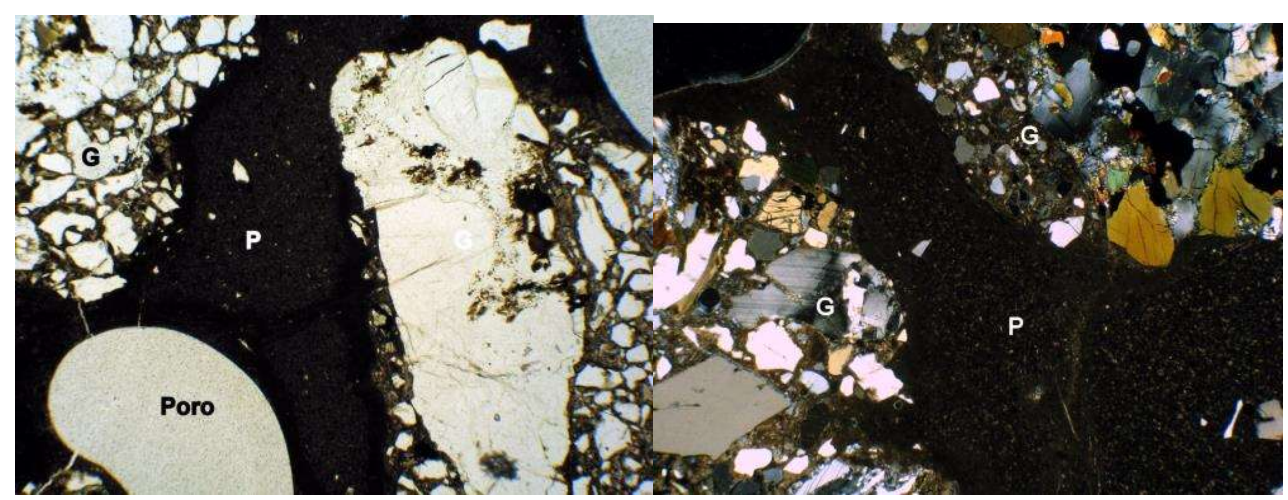

(a)

(b)

Figura 7: Fotomicrografia com nicóis descruzados - Microscópio de luz transmitida - Aumento 25x.

A Figura 8 expõe detalhes do contato entre o agregado graúdo reciclado $(\mathrm{G})$ carbonatado e a pasta (P) não carbonatada em outro ponto da peça estudada. Nota-se a esquerda da imagem, junto ao poro (V), que a pasta $(P)$ já se apresenta carbonatada. Neste segmento, o contato entre a pasta $(P)$ e o agregado reciclado se dá de maneira gradual, dando origem a uma zona de transição (Z). 


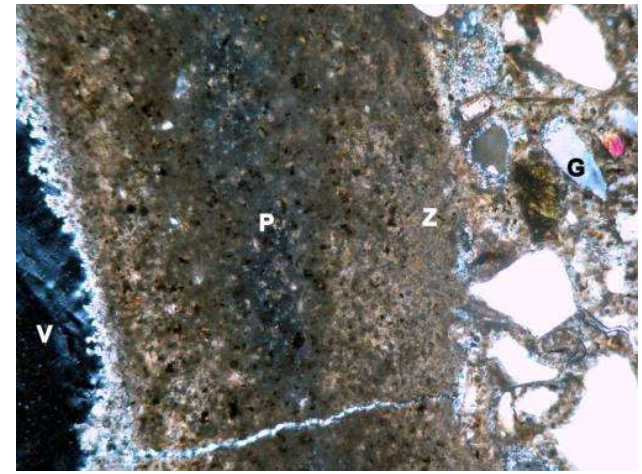

Figura 8: Fotomicrografia - Microscópio de luz transmitida - Aumento 50x.

O difratograma realizado na amostra após preparação - britagem e a moagem do material até passante na peneira \#325 (Figura 9).

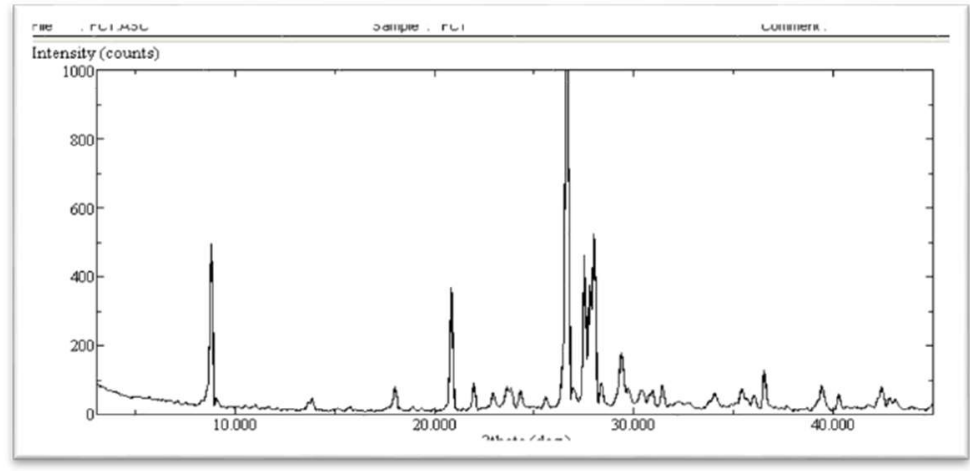

Figura 9: Difratometria de raios $X$.

\section{DISCUSSÃO}

No ensaio de massa específica no estado fresco, observa-se que à medida que a metodologia de produção do concreto permeável com resíduos foi sendo "calibrada", ou seja, ajustada de acordo com as necessidades do presente trabalho (incluindo a variabilidade dos resíduos e dos processos de adensamento), os resultados foram se aproximando do valor especificado durante o estudo de dosagem $\left(1600 \mathrm{~kg} / \mathrm{m}^{3}\right)$.

Verifica-se determinada congruência entre os resultados de massa específica no estado seco e índice de vazios com os valores comumente obtidos para concretos permeáveis. Para verificar a existência de uma diferença significativa entre as médias dos resultados e se os fatores abordados exercem influência sobre os valores obtidos, foi necessário estabelecer uma análise de variância da amostragem, também denominada ANOVA (Analysis of Variance). A ANOVA representa uma técnica estatística empregada na avaliação de afirmações acerca das médias de populações.

Os resultados dos ensaios foram submetidos, portanto, à uma análise de variância conforme Navidi (2015), sendo possível identificar que há, de fato, diferenças significativas entre os valores de massa específica no estado endurecido referentes às peças de $60 \mathrm{~mm}$ em detrimento às demais. Os índices de vazios, por sua vez, representam, estatisticamente, a mesma população, independentemente do tipo de corpo de prova.

Ainda acerca do índice de vazios, não obstante a divergência entre os autores sobre o limite superior 
deste parâmetro para concretos permeáveis, o qual pode variar entre 15\% a 25\% (TENNIS et al., 2004), 30\% (BATEZINI, 2013) ou 35\% (OLEK et al., 2003), os índices encontrados se aproximam de 20\%, indicado por Tennis et al. (2004) como valor ótimo entre resistência e permeabilidade.

Os coeficientes de variação alusivos aos ensaios de determinação de massa específica são baixos, o que denota satisfatória qualidade da produção dos corpos de prova. Quanto aos coeficientes obtidos a partir da determinação do índice de vazios, já se esperavam valores elevados em virtude da descontinuidade de massa associada ao concreto permeável, sobretudo por possuir resíduos de concreto em sua composição.

Com relação a resistência à compressão em corpos de prova cilíndricos, é possível observar uma variação considerável entre os resultados advindos de amostras de resíduo distintas e até mesmo entre os CPs produzidos pelo mesmo resíduo, corroborada pelo coeficiente de variação obtido: $16,79 \%$. Contudo, mesmo com essa discrepância entre os valores, que pode ser associada à variabilidade dos agregados reciclados e à própria natureza anisotrópica dos concretos permeáveis, os resultados de resistência à compressão alcançados se adequam satisfatoriamente à faixa de valores para concretos permeáveis.

O desempenho é ainda mais notável quando comparado aos resultados de trabalhos anteriores quanto à resistência à compressão. Goede (2009), executando ensaios de resistência à compressão de amostras cilíndricas de concreto permeável com índices de vazios variando entre $26 \%$ e $28 \%$, encontrou valores próximos a $10 \mathrm{MPa}$. Já os resultados alcançados por Batezini (2013) em sua pesquisa variavam entre 6,02 MPa e 10,17 MPa, com um índice de vazios médio de aproximadamente $25 \%$.

Apesar de terem sidos produzidos com agregados distintos, que demonstraram nessa pesquisa ter grande influência sobre a variação das propriedades físicas e mecânicas do concreto, identificou-se um padrão de ruptura à flexão apresentado pelos prismas: em todas as oportunidades o rompimento ocorreu no terço médio da seção longitudinal, que representa o segmento de momento fletor máximo.

Todos os valores obtidos atendem à especificação mínima quanto à resistência mecânica característica, definida pela NBR16416 (ABNT, 2015), para revestimento de pavimento de concreto permeável moldado no local. A norma limita a determinação da resistência à tração na flexão a valores superiores a 2 MPa para tráfego leve de veículos.

Com relação aos blocos, observa-se que os de espessura $60 \mathrm{~mm}$ alcançaram valores satisfatórios de resistência, permanecendo dentro do limite normativo; já as peças de $80 \mathrm{~mm}$ de espessura se mostraram menos resistentes quanto à compressão, mas mesmo não atendendo aos requisitos especificados em norma, atingiram valores muito próximos do limite. Essa diferença entre as peças se dá, entre outros aspectos, à variabilidade das propriedades das diferentes amostras de resíduo de concreto que compõem as peças.

Para o ensaio de módulo de elasticidade dinâmico, devido à sua composição naturalmente porosa, esperava-se que o módulo de do concreto permeável alcance valores inferiores aos obtidos pelos concretos convencionais que, segundo Batezini (2013), são da ordem de $28 \mathrm{GPa}$. Analisando-se, os valores obtidos do trabalho, observa-se que a média encontrada representa menos da metade do módulo de elasticidade definido para o CCP. Isso se deve ao maior índice de vazios inerente a materiais permeáveis que reduzem a 
Metodologia de dosagem e viabilidade em estudo do potencial de aplicação do resíduo de concreto como agregado graúdo para concretos

velocidade de propagação de ultrassom, uma vez que, por se tratar de uma onda mecânica, se propaga melhor num meio mais denso.

Já se comparando os resultados da atual pesquisa àqueles encontrados pelo próprio Batezini (2013) em seu estudo sobre concretos permeáveis, que giram entre $23 \mathrm{MPa}$ e $24 \mathrm{GPa}$, salvo eventuais variações na execução do ensaio ou diferenças técnicas entre os aparelhos utilizados, tem-se que os módulos de elasticidade obtidos para os concretos compostos por agregados reciclados correspondem a apenas $57 \%$, aproximadamente, da média referente aos compósitos produzidos com agregados naturais. Esse comportamento é esclarecido justamente pela presença dos resíduos de concreto na composição do material, que demonstraram maior taxa de absorção de água quando comparados aos agregados convencionais, apresentando, consequentemente, maior porosidade.

Verifica-se que todas as placas apresentaram um coeficiente de permeabilidade superior a $0,1 \mathrm{~cm} / \mathrm{s}$, que representa o mínimo especificado pela NBR 16416 (ABNT, 2015c), determinando a conformidade técnica do conjunto a respeito das prescrições normativas.

Os elevados resultados de coeficiente de permeabilidade alcançados por este estudo podem ser associados à utilização de resíduos de concreto na composição do material, haja vista a não aplicação de aditivos durante a concretagem. Essa conjectura é corroborada por Alves (2016) que encontrou, em seus estudos envolvendo a substituição gradual de agregado graúdo natural por resíduos de construção e demolição, coeficientes de permeabilidade entre 1,19 cm/s e 2,24 cm/s, análogos aos obtidos na presente pesquisa. Concomitantemente ao aumento da porcentagem de substituição do agregado natural pelo reciclado, observou-se um acréscimo nos índices de permeabilidade do concreto.

Analisando-se estatisticamente os resultados obtidos, os altos coeficientes de variação estão relacionados à grande dispersão dos valores encontrados entre as placas. Isso se deve, sobretudo, à variabilidade no processo de acomodação das partículas e à consequente variação do índice de vazios, propriedade intimamente associada à permeabilidade do compósito. Especialmente para as placas com 60 $\mathrm{mm}$ de espessura, que foram as primeiras a serem produzidas, quando os procedimentos de moldagem e adensamento ainda estavam sendo calibrados.

Esse fato é reforçado contrapondo-se os coeficientes obtidos nas placas de espessuras distintas, com o auxílio da análise de variância adotada no estudo, pela qual detectou-se a existência de diferença significativa entre as amostras. Neste contexto, o panorama é agravado, também, pela utilização das amostras de resíduos - cujas propriedades estão intimamente ligadas às do produto final - na fabricação das placas menos espessas.

Para os modelos reais, os resultados de determinação da massa específica do concreto fresco para as peças do passeio e para a vaga do estacionamento apresentaram resultados similares aos valores referentes às concretagens precedentes: $1678,4 \mathrm{~kg} / \mathrm{m}^{3}$ e $1622,6 \mathrm{~kg} / \mathrm{m}^{3}$, respectivamente.

Quanto aos ensaios de determinação do coeficiente de permeabilidade, realizados tanto no concreto moldado diretamente na vaga de estacionamento quanto nos blocos para pavimentação intertravada 
Metodologia de dosagem e viabilidade em estudo do potencial de aplicação do resíduo de concreto como agregado graúdo para concretos permeáveis sem uso de aditivos

PAULA JUNIOR, A. C.; OLIVEIRA, T. M.; POLISSENI, A. E.; MARQUES, G. L. O.; BASTOS, P. K. X.

assentadas no passeio, obtiveram-se resultados superiores até mesmo aos valores encontrados em laboratório: $2,46 \mathrm{~cm} / \mathrm{s}$ e $3,03 \mathrm{~cm} / \mathrm{s}$, respectivamente. O que demonstra, mais uma vez, o enorme potencial drenante do material.

Pelas análises para microscopia de luz transmitida e de difratometria de raios $X$, a partir da fotomicrografia com nicóis (filtros polarizados) descruzados é possível observar os agregados graúdos reciclados envolvidos pela pasta e um poro do concreto permeável. Odifratograma realizado na amostra após preparação demonstra que o concreto produzido é composto por minerais relacionados aos agregados reciclados de concreto, quartzo, feldspato, mica e piroxênio. Além desses, é possível identificar portlandita $\left(\mathrm{Ca}(\mathrm{OH})_{2}\right)$, calcita e minerais anidros de cimento.

\section{CONCLUSÕES}

As análises do comportamento mecânico e hidráulico do material concebido na presente pesquisa, demonstram a viabilidade técnica das metodologias de dosagem, mistura, moldagem e adensamento desenvolvidas. O material produzido pode ser caracterizado como um produto de inovação tecnológica, em vista da inexistência de estudos prévios acerca do potencial de fabricação do concreto permeável com 100\% de substituição do agregado convencional por resíduo de concreto. Da mesma maneira, a elaboração de uma metodologia de dosagem própria, sem a aplicação de qualquer tipo de aditivo, também corrobora com o caráter inovador do compósito. Tudo isso seguindo como referência a norma que regulamenta o uso de revestimentos permeáveis - NBR 16416 (ABNT, 2015) -, estabelecida originalmente para agregados de origem pétrea.

Ademais, foram encontrados valores condizentes com a literatura, apesar da grande dispersão entre os resultados de índice de vazios e os de massa específica, verificada pelos seus coeficientes de variação. $O$ que já era esperado, em função da variabilidade associada ao concreto permeável. Além de sua constituição heterogênea, onde há descontinuidade de massa e formação de vazios não controlados, o emprego de resíduos de concretos com origens distintas potencializa essa característica.

O mesmo fenômeno ocorreu com os resultados obtidos do ensaio de determinação do coeficiente de permeabilidade, que demonstraram o excelente potencial drenante do compósito elaborado. Todas as placas submetidas ao teste descrito pela NBR 16416 (ABNT, 2015c) obtiveram coeficientes superiores ao limite normativo, equivalente a $10^{-3} \mathrm{~m} / \mathrm{s}$. Diante desse panorama, permite-se ponderar sobre a incorporação de determinada quantidade de agregado miúdo à mistura de concreto permeável, com o intuito de incrementar sua resistência mecânica, à medida que a condutividade hidráulica permaneça compatível ao valor estipulado pela norma. Quanto aos testes realizados na vaga experimental, verificou-se que a permeabilidade do sistema com toda a estrutura do pavimento já implantada é análoga à medida em laboratório.

Os valores de resistência mecânica obtidos também estão sujeitos à variação descrita acima. Como comprovado na análise dos resultados, a resistência mecânica dos corpos de prova depende intrinsecamente 
das características do agregado que os compõem. Constatou-se que os concretos confeccionados a partir de agregados com elevados índices de abrasão Los Angeles alcançavam valores reduzidos de resistência à compressão. De fato, deve-se considerar que quanto maior a resistência do concreto que deu origem ao resíduo reciclado, maior a resistência do produto final.

Em relação à estrutura interna do concreto permeável constituído por resíduos de concreto, foi possível identificar que o rompimento do material ocorre no próprio agregado. Haja vista que, diferentemente do comportamento observado em concretos convencionais, onde a zona de interface entre o agregado a matriz cimentícia representa a fase mais vulnerável do concreto, o agregado passa a se tornar a região de maior fragilidade do material, mais precisamente na zona de interface antiga. À vista de toda essa problemática envolvendo a variabilidade dos resíduos, a produção de concreto permeável com utilização de agregados reciclados de concreto deve ser precedida de um controle de caracterização rigoroso dos materiais.

De modo geral, o presente estudo evidenciou o grande potencial de utilização de agregados reciclados de concreto na produção de concretos permeáveis. Os diversos benefícios econômicos e ambientais associados à aplicação de revestimentos de concreto permeável na pavimentação urbana se potencializam a partir da utilização de RCC em sua composição. Principalmente em relação a temas envolvendo a redução da geração desses resíduos e do consumo de recursos naturais.

\section{REFERÊNCIAS}

ABNT. Associação Brasileira de Normas Técnicas. NBR 13292: Solo: Determinação do coeficiente de permeabilidade de solos granulares a carga constante. Rio de Janeiro: ABNT, 1995.

ABNT. Associação Brasileira de Normas Técnicas. NBR NM 51: Agregado graúdo: Ensaio de abrasão Los Angeles. Rio de Janeiro: ABNT, 2001.

ABNT. Associação Brasileira de Normas Técnicas. NBR NM 46: Agregados: Determinação do material fino que passa através da peneira 75 um, por lavagem. Rio de Janeiro: ABNT, 2003.

ABNT. Associação Brasileira de Normas Técnicas. NBR 10004: Resíduos da construção civil sólidos. Diretrizes para projeto, implantação e operação. Rio de Janeiro: ABNT, 2004.

ABNT. Associação Brasileira de Normas Técnicas. NBR NM 45: Agregados: Determinação da massa unitária e do volume de vazios. Rio de Janeiro: ABNT, 2006.

ABNT. Associação Brasileira de Normas Técnicas. NBR 5739: Concreto: Ensaios de compressão de corpos-de-prova cilíndricos. Rio de Janeiro: ABNT, 2018a.

ABNT. Associação Brasileira de Normas Técnicas. NBR 9833: Concreto fresco: Determinação da massa especifica, do rendimento e do teor de ar pelo método gravimétrico. Rio de Janeiro: ABNT, 2008b.
ABNT. Associação Brasileira de Normas Técnicas. NBR 7211: Agregados para concreto: Especificação. Rio de Janeiro: ABNT, 2009a.

ABNT. Associação Brasileira de Normas Técnicas. NBR NM 53: Agregado graúdo: Determinação da massa específica, massa específica aparente e absorção de água. Rio de Janeiro: ABNT, 2009b.

ABNT. Associação Brasileira de Normas Técnicas. NBR 12142: Determinação da resistência à tração na flexão de corpos de prova prismáticos. Rio de Janeiro: ABNT, 2010.

ABNT. Associação Brasileira de Normas Técnicas. NBR 9781: Peças de concreto para pavimentação: Especificação e métodos de ensaio. Rio de Janeiro: ABNT, 2013.

ABNT. Associação Brasileira de Normas Técnicas. NBR 5738: Concreto: Procedimento para moldagem e cura de corposde-prova. Rio de Janeiro: ABNT, 2015a.

ABNT. Associação Brasileira de Normas Técnicas. NBR 8953: Concreto para fins estruturais: Classificação pela massa específica, por grupos de resistência e consistência. Rio de Janeiro: ABNT, 2015b.

ABNT. Associação Brasileira de Normas Técnicas. NBR 16416: Pavimentos permeáveis de concreto: Requisitos e procedimentos. Rio de Janeiro: ABNT, 2015c.

$\mathrm{ACl}$. American Concrete Institute. Committee 522. ACI 522R10: Pervious Concrete. Michigan: Farmington Hills, 2010. 
ACIOLI, L. A.. Estudo experimental de pavimentos permeáveis para o controle do escoamento superficial na fonte. Dissertação (Mestrado em Engenharia) Universidade Federal do Rio Grande do Sul, Porto Alegre, 2005.

ALVES, P. B.. Concreto permeável para pavimentação urbana com uso de resíduos de construção e demolição produzidos na usina de reciclagem de São José do Rio Preto. Dissertação (Mestrado em Engenharia Civil) Universidade Estadual Paulista, Ilha Solteira, 2016.

BATEZINI, R.. Estudo preliminar de concretos permeáveis como revestimento de pavimentos pra áreas de veículos leves. Dissertação (Mestrado em Engenharia) - Escola Politécnica da Universidade de São Paulo, São Paulo, 2013.

CANHOLI, A. P.. Drenagem urbana e controle de enchentes. São Paulo: Oficina de Textos, 2005.

CARDOSO, F. J. A.. Ambientes fluviais urbanos: novos paradigmas de projeto. Tese (Doutorado em Urbanismo) Pontifícia Universidade Católica de Campinas, São Paulo, 2017.

CONAMA. Conselho Nacional do Meio Ambiente. Ministério do Meio Ambiente. Resolução CONAMA no 307, de 5 de julho de 2002. Estabelece diretrizes, critérios e procedimentos para a gestão dos resíduos da construção civil. Brasília: CONAMA, 2002.

GOEDE, W. G.. Pervious concrete: investigation into structural performance and evaluation of the applicability of existing thickness design methods. Thesis (Master in Engineering) - Washington State University, Washington, 2009.

HÖLTZ, F. C.. Uso de concreto permeável na drenagem urbana: análise da viabilidade técnica e do impacto ambiental (Mestrado em Engenharia) - Universidade Federal do Rio Grande do Sul, Porto Alegre, 2011.

LAMB, G. S.. Desenvolvimento e análise do desempenho de elementos de drenagem fabricados em concreto permeável. Dissertação (Mestrado em Engenharia Civil) Universidade Federal do Rio Grande do Sul, Porto Alegre, 2014.

MONTES, F.; HASELBACH, L.. Measuring Hydraulic Conductivity in Pervious Concrete. Environmental Engineering Science, v.23, p.960-969, 2006.

NAVIDI, W. C.. Statistics for engineers and scientists. 4 ed. New York: McGraw-Hill Education, 2015.

NRMCA. National Ready Mixed Concrete Association. Freeze thaw resistance of pervious concrete. Silver Spring: NRMCA, 2004.

OLEK, J.; WEISS, W. J.; NEITHALATH, N.; MAROLF, A.; SELL, E.; THORNTON, W. D.. Development of quiet and durable porous Portland cement concrete paving materials. Final Report, the Institute for Safe, Quiet, and Durable Higways. SQDH 2003-5. Purdue: Center of Advanced Cement Based Materials, 2003.

PINTO, L. L. C. A.. O desempenho de pavimentos permeáveis como medida mitigadora da impermeabilização do solo urbano. Tese (Doutorado) Escola Politécnica da Universidade de São Paulo, São Paulo, 2011.

SCHAEFER, V.; WANG, K.; SULEIMAN, M.; KEVERN, J.. Mix design development for pervious concrete in cold weather climates. Final Report, Civil Engineering, National Concrete Pavement Technology Center. Ames: Iowa State University, 2006.

TENNIS, P. D.; LEMING, M. L.; AKERS, D. J.. Pervious concrete pavements. EB302. Skokie: Portland Cement Association, 2004.

A CBPC - Companhia Brasileira de Produção Científica (CNPJ: 11.221.422/0001-03) detém os direitos materiais desta publicação. Os direitos referem-se à publicação do trabalho em qualquer parte do mundo, incluindo os direitos às renovações, expansões e disseminações da contribuição, bem como outros direitos subsidiários. Todos os trabalhos publicados eletronicamente poderão posteriormente ser publicados em coletâneas impressas sob coordenação da Sustenere Publishing, da Companhia Brasileira de Produção Científica e seus parceiros autorizados. Os (as) autores (as) posteriormente ser publicados em coletâneas impressas sob coordenação da Sustenere Publishing, da Companhia Brasileira de Produção Cientifica e seus parce
preservam os direitos autorais, mas não têm permissão para a publicação da contribuição em outro meio, impresso ou digital, em português ou em tradução. 